\title{
Reproductive capacity of an endangered and recovering population of humpback whales in the Southern Hemisphere
}

\author{
Guillaume Chero ${ }^{1,2,3,4, *}$, Roger $_{\text {Pradel }^{2}}$, Solène Derville ${ }^{1,3}$, Claire Bonneville $^{1,3}$, \\ Olivier Gimenez ${ }^{2}$, Claire Garrigue ${ }^{1,3}$
}

${ }^{1}$ UMR Entropie (IRD, Université de La Réunion, CNRS), BP A5, 98848 Nouméa, New Caledonia

${ }^{2}$ CEFE, CNRS, Université Montpellier, Université Paul Valéry Montpellier 3, EPHE, IRD, 34293 Montpellier, Cedex 5, France

${ }^{3}$ Opération Cétacés, BP 12827, 98802 Nouméa, New Caledonia

${ }^{4}$ Department of Ecological Dynamics, Leibniz-Institut for Zoo and Wildlife Research (IZW), Alfred-Kowalke-St. 17, Berlin 10315, Germany

\begin{abstract}
Estimating demographic parameters is essential to assessing the recovery potential of severely depleted populations of marine mammal species such as the baleen whales, which were decimated by commercial whaling of the past century. The Oceania humpback whale Megaptera novaeangliae population is classified as endangered by the IUCN because of low numbers and a slow recovery rate. Nevertheless, an anomalously strong increase has recently been detected in the New Caledonia breeding population. To determine the drivers of population growth, reproductive parameters were estimated for the first time for a humpback whale population of Oceania. Based on an extensive monitoring program (1995-2018), recapture histories were reconstructed for 607 females and incorporated in multi-event capture-recapture models. As the females' ages were generally unknown $(87 \%), 2$ models with contrasting age scenarios were investigated. For females of unknown age, the mature scenario assumed maturity at the first encounter, while the immature scenario assumed immaturity within $7 \mathrm{yr}$ after the first encounter, unless the female was encountered breeding. These models respectively resulted in a calving interval of $1.49 \mathrm{yr}$ (95\% CI: 1.21-2.08) or 2.83 yr (95\% CI: $2.28-3.56)$ and a calving rate of 0.67 or 0.35 . The relatively high calving rate modelled by the mature model is consistent with high pregnancy rates recently observed in the migratory corridors of the Kermadec Islands and on the feeding grounds of the Antarctic Peninsula. Therefore, our results suggest that the recovery of the New Caledonia humpback whale population from past exploitation may be partially driven by an increased reproductive capacity.
\end{abstract}

KEY WORDS: Calving interval $\cdot$ Calving rate $\cdot$ Humpback whales $\cdot$ New Caledonia $\cdot$ Pacific population $\cdot$ Recovery $\cdot$ Sexual maturity

\section{INTRODUCTION}

In the context of biodiversity loss and decrease in natural populations (Barnosky et al. 2011, Pimm et al. 2014), understanding the recovery of a population following intense exploitation is an important issue in conservation. Baleen whale populations were heavily impacted by commercial whaling over the last century, with an estimated 2 million whales hunted (Clapham \& Baker 2002). When commercial exploita-

${ }^{*}$ Corresponding author: chero@izw-berlin.de tion was officially brought to an end, humpback whale Megaptera novaeangliae populations were near extinction (Tønnessen \& Johnsen 1982, Jackson et al. 2015), leading the IUCN to classify them as an endangered species worldwide in 1986. Since then, most of the populations have increased, and in 2008 the species' status was changed from Vulnerable to Least Concern, with the exception of the Arabic and Oceania populations that were changed to Endangered (Childerhouse et al. 2008, Minton et al. 2008). 
Long-lived mammal species, such as humpback whales, are characterized by low temporal fluctuation in survival rate (canalization theory, Gaillard \& Yoccoz 2003), thus slowing down the resilience of populations following intense exploitation (Gaillard \& Yoccoz 2003, Gamelon et al. 2014). Moreover, because of their large size, they theoretically invest more energy in survival than reproduction, leading to a low potential growth rate and a slow population recovery (Lebreton 2006). The average intrinsic growth rate of humpback whale populations has been estimated at between 7.3 and $8.6 \% \mathrm{yr}^{-1}$, with a maximum plausible rate of $11.8 \% \mathrm{yr}^{-1}$ (Zerbini et al. 2010). This maximum growth rate was estimated primarily using reproductive parameters obtained for Northern Hemisphere populations (Clapham \& Mayo 1987, Barlow \& Clapham 1997). More recently, Wedekin et al. (2017) conducted a metaanalysis to explore the differences in worldwide growth rate and predicted a higher growth rate for Southern Hemisphere populations (12.2\%) than for Northern Hemisphere ones $(7.7 \%)$. The authors suggest that Southern Hemisphere humpback whales may display shorter inter-birth intervals and higher survival rates and possibly breed at a younger age when conditions are favourable. However, parameters such as calving rates have rarely been calculated for Southern Hemisphere populations (Rankin et al. 2014).

The potential recovery of an endangered population in the Southern Hemisphere - the humpback whale population of Oceania (including humpback whales wintering in the South Pacific islands from New Caledonia to French Polynesia; Childerhouse et al. 2008) — has recently been investigated through population dynamics analysis. Jackson et al. (2015) estimated a population growth rate of $8.2 \% \mathrm{yr}^{-1}$ between 2010 and 2015 and suggested that the population size was at $47 \%$ of preexploitation levels in 2015. The humpback whale breeding sub-stock E2 (IWC 2005), which migrates annually from feeding areas in the Southern Ocean to breeding grounds in New Caledonia, belongs to this population (Constantine et al. 2012). Sub-stock E2 has recently been characterized by an anomalous increase in abundance and a high realized growth rate of $15 \%$ (Garrigue et al. 2012, Orgeret et al. 2014), well above the maximum plausible rate of $11.8 \%$ calculated by Zerbini et al. (2010). Although previous work has put forward immigration as a possible cause of the high growth rate (Orgeret et al. 2014), we suggest breeding capacity as an alternative hypothesis. Based on an extensive monitoring program conducted for more than 2 decades in New Caledonia, we provide the first estimation of reproductive parameters for a humpback whale population in Oceania.

\section{MATERIALS AND METHODS}

\subsection{Data collection}

Humpback whale surveys were conducted in the austral winter (July-September) between 1995 and 2018 in the breeding ground of New Caledonia, South Pacific (Garrigue et al. 2001). The survey effort was determined to maximize the chances of a whale encounter while accounting for common cetacean survey limitations: weather conditions, harbour proximity and vessel capacity (Derville et al. 2018). The search effort primarily focused on the coastal waters of the South Lagoon aboard a $6 \mathrm{~m}$ rigid-hulled inflatable boat. Surveys did not follow a systematic or explicitly randomized sampling technique but rather a haphazard sampling regime to maximize encounters with whales (Derville et al. 2019). Surveys were conducted in closing mode, as cetaceans were approached upon detection, and a focal follow was conducted at each group encounter. The presence or absence of a calf was recorded. Humpback whales were approached to photograph the underside of their fluke and to collect a skin sample (biopsy, Lambertsen 1987). Humpback whales were then individually identified by photo-identification (Katona \& Whitehead 1981) and/or genotyping on 16 previously published micro-satellite loci (Garrigue et al. 2004, Olavarría et al. 2007, Baker et al. 2013). To identify the sex of each individual sampled, molecular sexing was performed by amplification of a male-specific SRY marker with a positive control ZFX/ZFY (Aasen \& Medrano 1990, Gilson et al. 1998) as described in Garrigue et al. (2004).

Capture-recapture histories were then constructed for females that had been genetically identified at least once in their life. During each encounter, females' identity was validated via genotyping, photoidentification or a combination of the 2 methods. Based on the recapture histories, 2 breeding statuses were defined: a female observed with a calf was considered as a breeding female (B), and a female without a calf was considered a non-breeding female (NB). In addition, females were not necessarily genetically identified and genetically sexed upon their first encounter (in the case when females were only identified via photo-identification at the time). Including these encounters prior to the year of the first genotyping may bias survival estimates, but is useful to estimate breeding parameters. Hence, to estimate survival only after genotyping occurred, the first year of genotyping was also recorded in the capturerecapture history (see GI in Table S1 in Supplement 1 at 
www.int-res.com/articles/suppl/m643p219_supp1.xlsx). To estimate survival only after genotyping occurred, female status at each encounter was assigned a code whether the female had been genotyped upon its first encounter (GI) or not (NG). Genetic identification is usually performed several times throughout a female's history of capture, but only the first one is referenced for the purpose of this study. In summary, for each breeding season included in this study, females could either be not encountered, encountered non-breeding and genetically identified (NB-GI), encountered breeding and genetically identified (B-GI), encountered non-breeding and not genetically identified (NB-NG) or encountered breeding and not genetically identified (B-NG, Table S1).

\subsection{Multi-event model description}

As a preliminary approach to understanding the data structure, we ran goodness of fit (GOF) tests designed for the conditional Arnason-Schwarz model (CAS, Pradel et al. 2003), where survival, breeding and detection probabilities are time specific, using the R2ucare package (Gimenez et al. 2018). The only detected departure from the assumptions of the CAS model is a high frequency of individuals observed only once (Test 3.GR, p = 0.001, see Pradel et al. 2005 for details of the test). This is usually interpreted as the presence of transient individuals in the sample, but may also result from the inadequacy of the CAS model to account for other differences among individuals (Genovart \& Pradel 2019).

Reproductive parameters were calculated using ESURGE software (Choquet et al. 2009) based on multievent models (Pradel 2005). Two separate multi-event models were implemented to account for age to sexual maturity. Zerbini et al. (2010) and Rankin et al. (2014) reported humpback whale sexual maturity at 5.9 to 11 and 4.23 to 13.50 yr, respectively. Furthermore, in our dataset, females of known age (first encountered as calves, $13 \%$ of individuals) were at least $8 \mathrm{yr}$ old when they were encountered with a breeding status ( $\mathrm{n}=2$ females). Hence, all females of known age were considered mature $8 \mathrm{yr}$ after their first encounter as calves. For other females, the true age was unknown, and sexual maturity was therefore introduced through 2 different scenarios which were analysed independently: one where females were considered as mature at the first encounter (SMa), and another where females were considered immature at the first encounter unless encountered breeding (SIm). In the latter scenario, maturity was acquired either $7 \mathrm{yr}$ after their first encounter or at the first breeding event encountered within $7 \mathrm{yr}$ after their first encounter.

A first initial state matrix was set up to define whether individuals were genetically identified and sexed or not at first encounter (C currently and L latter status in state matrix $\pi$, given in Supplement 2, www.int-res.com/articles/suppl/m643p219_supp2.pdf). A second matrix defined the known or presumed age of the individual at first encounter, depending on the scenario (SIm or SMa). The model included the proportion of breeders among the mature individuals observed for the first time (SMa scenario only), the survival probabilities $(\phi)$, the probabilities of transition between breeding statuses $(\psi)$ and the detection probabilities $(p)$, each described by a separate matrix (Supplement 2). Survival was estimated as constant over time, and related to 2 age classes: survival over the first year (calf survival), and survival over the rest of the whales' lives (juvenile and adult survival). Transition probabilities were also considered constant within each breeding status, to obtain a mean reproductive capacity in the population. Detection probability and initial state were tested as either constant or fluctuating over time, the former additionally depending on breeding status. Finally, we also considered the possibility that there were transient females, by estimating a separate survival probability for newly encountered individuals (effect $[c]$ on survival). We tested several model parameterizations and selected the most parsimonious combination using Akaike's information criterion (Burnham \& Anderson 2002).

\subsection{Reproductive parameters}

Multi-event models allowed the estimation of distinct breeding probabilities $\mathrm{p}$ following a breeding episode:

$$
\mathrm{p}\left(\text { breeding }_{t} \mid \text { breeding }_{t-1}\right)=\mathrm{p}(B \mid B)
$$

and not following a breeding episode:

$$
\mathrm{p}\left(\text { breeding }_{t} \mid \text { not breeding } \text { br-1 }\right)=\mathrm{p}(B \mid N B)
$$

These 2 conditional probabilities allowed the calculation of the probability $\gamma_{t}$, that 2 calving events were separated by a time interval $t$ :

$$
\begin{gathered}
\gamma_{1}=\mathrm{p}(B \mid B) \\
\gamma_{2}=\mathrm{p}(B \mid B) \times \mathrm{p}(B \mid N B) \\
\gamma_{3}=\mathrm{p}(N B \mid B) \times \mathrm{p}(N B \mid N B) \times \mathrm{p}(B \mid N B)
\end{gathered}
$$

The maximum interval considered was $10 \mathrm{yr}$, as it was the longest calving interval observed in the 
Table 1. Summary relating the number of parameters and evaluation metrics for the 4 best multi-event models under 2 different scenarios applied to 607 female humpback whales encountered in New Caledonia between 1995 and 2018. The 2 bold models are the ones selected. Multi-event models were based on an initial matrix $\pi$, survival parameters $\phi$, transition probabilities $\psi$ and detection probabilities $p$. Parameters could be constant (.), fluctuate in time $(t)$, vary by breeding status only $(b)$, be related to age $(a)$ and be the first genetic identification $(g)$. The initial matrix could account for sexual maturity following the 2 extreme scenarios, SMa and SIm. With the exception of individuals of known age, the immature scenario (SIm) considered all females as immature within $7 \mathrm{yr}$ after their first encounter (the model was also tested with a maturity of $5 \mathrm{yr}$ ) unless encountered breeding before then, and the second scenario (SMa) considered all females as mature at the first encounter. These models tested the impact of considering age at maturity and model structure. Akaike's information criterion (AIC), the difference of AIC across models ( $\triangle \mathrm{AIC}$ ), AIC weight and deviance are reported

\begin{tabular}{|c|c|c|c|c|c|c|c|}
\hline Model & $\begin{array}{l}\text { Age } \\
\text { class }\end{array}$ & $\begin{array}{c}\text { Age at } \\
\text { maturity }\end{array}$ & $\begin{array}{c}\text { Para- } \\
\text { meters } \\
\text { (n) }\end{array}$ & Deviance & AIC & $\Delta \mathrm{AIC}$ & $\begin{array}{c}\text { AIC } \\
\text { weight }\end{array}$ \\
\hline \multicolumn{8}{|l|}{ SIm model } \\
\hline $\begin{array}{l}\pi(\mathbf{S I m} \cdot \boldsymbol{g}) \cdot \boldsymbol{\phi}(\mathbf{\cdot}) \cdot \psi(\mathbf{a} \cdot \boldsymbol{b}) \cdot \boldsymbol{p}(\boldsymbol{b}) \\
\pi(\operatorname{SIm} . q . t) \cdot \phi(.) \cdot \psi(a . b) \cdot p(b)\end{array}$ & $\begin{array}{l}2 \\
2\end{array}$ & $\begin{array}{l}7 \\
7\end{array}$ & $\begin{array}{c}8 \\
31\end{array}$ & $\begin{array}{l}2051.7 \\
2011.41\end{array}$ & $\begin{array}{l}2065.77 \\
2073.41\end{array}$ & $\begin{array}{c}0 \\
7.7\end{array}$ & $\begin{array}{l}9.7 \mathrm{e}^{-1} \\
2.0 \mathrm{e}^{-2}\end{array}$ \\
\hline$\pi(\operatorname{SIm} . g \cdot t) \cdot \phi(.) \cdot \psi(a \cdot b) \cdot p(b)$ & 2 & 5 & 31 & 2316.3 & 2352.1 & 286 & $6.3 e^{-63}$ \\
\hline$\pi(\operatorname{SIm} . g) \cdot \phi(.) \cdot \psi(a \cdot b) \cdot p(b)$ & 2 & 5 & 8 & 2344.6 & 2362.6 & 296.9 & $3.3 \mathrm{e}^{-65}$ \\
\hline \multicolumn{8}{|l|}{ SMa model } \\
\hline$\pi($ SMa.g). $\phi(.) \cdot \psi(a . b) \cdot p(b)$ & 2 & 7 & 8 & 2776.64 & 2792.6 & 0 & $8.5 \mathrm{e}^{-1}$ \\
\hline$\pi($ SMa.g). $\phi(.) \cdot \psi(a . b) \cdot p(b)$ & 2 & 5 & 8 & 2780.1 & 2796.1 & 3.5 & $1.4 \mathrm{e}^{-1}$ \\
\hline$\pi($ SMa.g.t). $\phi(.) \cdot \psi(a . b) \cdot p(b)$ & 2 & 7 & 31 & 2746.21 & 2808.2 & 15.6 & $3.4 \mathrm{e}^{-4}$ \\
\hline$\pi($ SMa.g.t). $\phi(.) \cdot \psi(a . b) \cdot p(b)$ & 2 & 5 & 31 & 2749.6 & 2811.6 & 19.0 & $6.3 e^{-5}$ \\
\hline
\end{tabular}

Table 2. Values $( \pm \mathrm{SE})$ of the reproductive and population parameters estimated for 2 scenarios in a multi-event model calculated on 607 female humpback whales encountered in New Caledonia between 1995 and 2018. With the exception of individuals of known age, the immature scenario (SIm) considers all females as immature within 7 yr after their first encounter unless encountered breeding before then, and the second scenario (SMa) considers all females as mature at the first encounter. Four different parameters are reported for each class: probability of breeding during 2 consecutive years $\mathrm{p}(\mathrm{B} \mid \mathrm{B})$, probability of breeding the first year and not breeding the second year $\mathrm{p}(\mathrm{B} \mid \mathrm{NB})$, the calving interval (yr) estimated from the best multi-event model and the calving rate (inverse value of the calving interval)

\begin{tabular}{|lcc|}
\hline Parameter & Immature scenario (SIm) & Mature scenario (SMa) \\
\hline Survival 1 yr & $0.50 \pm 0.14$ & $0.33 \pm 0.10$ \\
Survival > 1 yr & $0.87 \pm 0.01$ & $0.90 \pm 0.01$ \\
Detection NB & $0.06 \pm 0.01$ & $0.11 \pm 0.02$ \\
Detection B & $0.28 \pm 0.04$ & $0.06 \pm 0.01$ \\
p(B।B) & $0.01 \pm 0.01$ & $0.82 \pm 0.04$ \\
p(B।NB) & $0.54 \pm 0.07$ & $0.36 \pm 0.07$ \\
Calving interval $(\mathrm{yr})$ & $2.83(95 \%$ CI: $2.28-3.56)$ & $1.49(95 \%$ CI: $1.21-2.08)$ \\
Calving rate & 0.35 & 0.67 \\
\hline
\end{tabular}

dataset. The mean calving interval was then calculated based on the different probabilities as:

$$
\sum_{t=1}^{10} t \gamma_{t}
$$

The calving rate was calculated as the inverse of the calving interval, to represent the annual proportion of females that breed (Civil et al. 2017).

\section{RESULTS}

A total of 607 females were individually genotyped, representing $39 \%$ of the total number of humpback whales genetically identified in New Caledonia (sex ratio: 1.5:1 [M:F]). Among these females, $26 \%$ ( $\mathrm{n}=$ 156) were observed at least once with a breeding status, and $13 \%(n=78)$ were first observed as calves. A total of 859 encounters were made, including 221 encounters where a calf accompanied a female. Breeding in consecutive years was observed in only 1 case.

Only the 4 best models are presented for each scenario (Table 1). Although the GOF test had detected a signal of transience, the best-supported multi-event model did not retain transience (in bold in Table 1). It included constant survival on 2 different age classes. It also included detection and transition probabilities depending on the breeding status (breeder or non-breeder) and age at maturity (see Supplement 2). The SIm model had a lower deviance than the SMa model (2051.7 and 2776.64, respectively, Table 1 ).

In both the SIm and the SMa models, survival was considerably lower for the first year as a calf (respectively $0.50 \pm 0.14$ and $0.33 \pm 0.10$, Table 2), compared to subsequent years $(0.87 \pm 0.01$ and $0.90 \pm 0.01$ ). The probability of detection differed between the 2 breeding statuses in the SIm model (NB detection $0.06 \pm 0.01$ vs. B detection $0.28 \pm 0.04)$ but not as much in the SMa model (NB detection $0.11 \pm 0.02 \mathrm{vs}$. B detection $0.06 \pm 0.01$ ).

Finally, the SMa model showed a probability to breed in consecutive years of 0.82 and a probability to breed the second year if non-breeding the first year of 0.36 . As a result, the calving interval in this 
mature scenario averaged 1.49 yr $(95 \%$ CI: $1.21-$ $2.08)$, and the calving rate was estimated at 0.67 (Table 2). On the other hand, the SIm model showed a probability to breed in consecutive years of 0.01 and a probability to breed the second year if nonbreeding the first year of 0.54 . Hence, the calving interval in this immature scenario averaged $2.83 \mathrm{yr}$ (95\% CI: 2.28-3.56), and the calving rate was estimated at 0.35 (Table 2).

\section{DISCUSSION}

In this study, we used a 24 yr recapture dataset where age was unknown to estimate female reproductive parameters and survival for the endangered humpback whale population of New Caledonia, while accounting for the impact of age at sexual maturity. This study provides the first estimates of calving rates for a humpback whale population breeding in Oceania.

\subsection{Detection of females on breeding grounds}

Although the GOF test detected a signal, which could be due to transience, transience was not retained in the final multi-event model. The transience signal detected by the GOF test reflects a lower probability of reencountering newly captured females. Here, such signal is likely to be due to age (Genovart \& Pradel 2019). Indeed, younger females have lower survival (Table 2) and may therefore die before being recaptured. True transience (i.e. individuals transiting through but not belonging to the study population, Genovart \& Pradel 2019) may not occur in New Caledonia. Indeed, interchange levels across neighbouring populations and breeding grounds of the South Pacific are marginal in comparison to breeding site fidelity (Garrigue et al. 2002, 2011, Olavarría et al. 2007). Although recent genetic analyses have highlighted potential exchanges between New Caledonia and the east Australian migratory corridor (Valsecchi et al. 2010, Steel et al. 2018), the genetic differentiation of females of both subpopulations is significant (Bonneville et al. 2017). The probability for a female of the New Caledonian subpopulation to occasionally give birth outside these waters is therefore expected to be low.

The transience effect detected by the GOF could also result from a lack of detection of whales otherwise present in the New Caledonian study region, which covers multiple breeding aggregations, some of them recently discovered. Given the heterogeneous levels of survey effort across years and especially across breeding aggregations (Derville et al. 2018), it is possible that some individuals favouring certain breeding aggregations over others (Garrigue et al. 2017) may have different detectability.

Alternatively, it is possible that newly captured females are not reencountered in New Caledonia, because they did not migrate and overwintered in their feeding grounds in some years. Indeed, based on the sex ratio measured over the east Australian migratory corridor $(2.4: 1 \quad[\mathrm{M}: \mathrm{F}])$ and in whaling catches, Brown et al. (1995) suggested that about half of the females in Antarctic area $\mathrm{V}$ did not migrate each year. Nevertheless, the sex ratio measured in New Caledonia over our study period (1.5:1 [M:F]) suggests a lower sex bias, indicating a potentially smaller proportion of non-migrant females.

Finally, in the SIm model, breeding females had a higher detection probability $(0.28 \pm 0.04)$ than nonbreeding females $(0.06 \pm 0.01)$. This is easily explained, as breeding females tend to stay longer in breeding grounds (Chittleborough 1965, Dawbin 1966), hence increasing their probability to be observed within a given season.

\subsection{Survival of females}

The survival of females $>1 \mathrm{yr}$ old between 0.87 and 0.90 estimated by our models is slightly lower than the survival of the entire population, estimated at 0.94 (Orgeret et al. 2014). It is also lower than the survival estimated for females from various populations of the Northern and Southern hemispheres (Table 3, Barlow \& Clapham 1997, Rosenbaum et al. 2002, Ramp et al. 2010, Rankin et al. 2014), even if some annual survivals as low as 0.566 (CI: 0.418-0.733) have been measured in the Gulf of Maine, North Atlantic (Rosenbaum et al. 2002). These low survival values could be explained in part by the presence of juveniles in our dataset, whose survival is expected to be lower than that of mature individuals (Caughley 1966). Moreover, survival is likely to increase progressively after sexual maturity, as older females might be able to withstand higher energetic expenses for calving, nursing and lactation because of their larger size (Robbins 2007). Finally, early breeding in a female's life may affect its survival, as energy is allocated to reproduction rather than growth.

The survival of calves estimated by the SIm and SMa models was also lower than the estimates made in other populations of humpback whales around the 
Table 3. Humpback whale reference values of survival rates estimated across the globe

\begin{tabular}{|c|c|c|c|c|}
\hline Age & Hemisphere & Region & Survival rate & Reference \\
\hline \multirow[t]{4}{*}{$<1 \mathrm{yr}$} & Northern & Gulf of Maine, USA & 0.875 (SE: 0.047) & Barlow \& Clapham (1997) \\
\hline & & Gulf of Maine, USA & 0.664 (CI: $0.517-0.784$ ) & Robbins (2007) \\
\hline & & Gulf of Maine, USA & 0.702 & Rosenbaum et al. (2002) \\
\hline & & Hawaii and Alaska, USA & $0.482-0.759$ & Gabriele et al. (2001) \\
\hline \multirow[t]{4}{*}{$>1$ yr (females only) } & Northern & St Lawrence, Canada & 0.992 (CI: 0.985-0.999) & Ramp et al. (2010) \\
\hline & & Gulf of Maine, USA & 0.96 (SE: 0.008) & Barlow \& Clapham (1997) \\
\hline & & Gulf of Maine, USA & 0.964 (CI: 0.946-0.976) & Rosenbaum et al. (2002) \\
\hline & Southern & Hervey Bay, Australia & 0.98 (CI: 0.96-0.99) & Rankin et al. (2014) \\
\hline
\end{tabular}

world (Baker et al. 1987, Clapham \& Mayo 1987, Barlow \& Clapham 1997, Craig \& Herman 2000). However, it must be noted that our values are not directly comparable to those available in the literature, as they were estimated (1) in a breeding area and (2) for female calves only. Hence, the differences observed could be caused by higher mortality of female calves compared to males or by higher mortality over the first calf's migration from breeding to feeding grounds. Moreover, survival of calves has been shown to vary greatly from one year to another (Rosenbaum et al. 2002), with exceptionally low survival estimated in some years (e.g. 0.142 [CI: 0.0220.550] in 1994-1995 in the Gulf of Maine, Rosenbaum et al. 2002).

\subsection{Calving interval}

In the absence of information on the exact age of females, we estimated the mean calving interval for 2 different sexual maturity scenarios, which we analysed separately. In essence, neither of these 2 sexual maturity scenarios is an exact reflection of the reality, as the real proportion of immature females in the population remains unknown. The reality lies inbetween the 2 scenarios, as do the resulting estimates of the females' reproductive parameters.

While they were applied to the same recapture dataset, the SIm model had a lower deviance than the SMa, hence indicating a better fit. In addition, the SIm model may be considered more conservative, as it estimated reproductive parameters using only the parts of recapture histories during which females were mature without doubt. The values issued from SIm (calving interval at 2.83 yr [95\% CI: 2.28-3.56] and calving rate at 0.36 ) are in agreement with the estimates from the Northern Hemisphere (2.38 yr in the Gulf of Maine, Barlow \& Clapham 1997) and the
Southern Hemisphere (2.78 yr in Australia, Rankin et al. 2014). The resulting calving rate estimated in southeastern Alaska (0.37, Baker et al. 1987) is also consistent with the SIm model's output. However, the comparison between populations originating from the 2 hemispheres must be considered with caution, as Wedekin et al. (2017) showed significant geographic differences in growth rate, especially between the Southern $(12.21 \%)$ and Northern $(7.74 \%)$ hemisphere populations. These differences were attributed to spatial variability in productivity and prey availability (Brodie 1975, Murphy et al. 2007). The only other Southern Hemisphere study currently comparable to our results was conducted on the east coast of Australia using a multi-event model and yielded a calving interval of 2.78 yr (95\% CI: 2.233.68, Rankin et al. 2014).

Alternatively, the SMa model showed an unusually small calving interval of $1.49 \mathrm{yr}$ (95\% CI: 1.21-2.08), and the calving rate was estimated at 0.67 . This high reproductive capacity suggests a relatively high probability for females to breed in consecutive years. Post-partum ovulation and calving in consecutive years is thought to be rare (Chittleborough 1965), and it was observed only once in our recapture dataset. Nevertheless, a high calving rate in New Caledonia would be in accordance with several recent studies investigating pregnancy rates based on progesterone concentrations in the South Pacific and Southern Ocean (Pallin et al. 2018, Riekkola et al. 2018). Riekkola et al. (2018) estimated that $56.7 \%$ of females were pregnant at Raoul Island (Kermadec, New Zealand), an island considered to be part of the southward migratory corridor of the New Caledonian humpback whale population (Garrigue et al. 2016, Riekkola et al. 2018). This value is close to our estimated calving rate of $67 \%$. Pallin et al. (2018) found a pregnancy rate of up to $86 \%$ in the Antarctic peninsula, a feeding ground known for its proximity to the 
Bellinghausen Sea, where humpback whales of Oceania have been followed with satellite tracking (Garrigue et al. 2018, Riekkola et al. 2018). These results converge towards the hypothesis that the South Pacific populations of humpback whales may be characterized by a high reproductive capacity, which could explain the higher growth rates observed in the Southern Hemisphere.

\subsection{High reproductive capacity in the South Pacific}

Several hypotheses can be brought forward to explain why humpback whales of the Southern Hemisphere may presently have higher reproductive capacities. First, calving rates may be related to the age structure of a population, as the reproductive capacity of mammals is known to often be related to the age of individuals (Clutton-Brock 1984). Riekkola et al. (2018) investigated the age structure of the humpback whales sampled in Raoul Island, revealing the rarity of individuals more than $30 \mathrm{yr}$ old and an average age of 13.8 yr. Females from this age class sampled in 2015 in Raoul Island would have been born around 2001. Therefore, they would have reached sexual maturity about 8 yr later, around 2009, and could have contributed to the increase in abundance recently measured in New Caledonia (Garrigue et al. 2012). We can hypothesize that younger and more fertile females are more abundant today in the humpback whale populations of Oceania. On average, these young females would therefore have more calves than the older generations that have survived the industrial whaling era. Epigenetic aging of humpback whales (Polanowski et al. 2014) would be of great interest to relate age and reproductive capacity at individual and population levels.

Second, a high reproductive capacity could also be caused by an evolution of the reproductive parameters at the individual level (Conover et al. 2009). The anthropogenic pressure caused by commercial whaling may have led to a modification of breeding parameters in large whales (i.e. age at maturity or birth interval). For instance, Kato (1995) highlighted an increase in the reproductive capacity of Antarctic minke whales Balaenoptera bonaerensis following commercial whaling and suggested that this phenomenon was linked to reduced competition with other baleen whales for food resources. As a second hypothesis, the birth interval observed in New Caledonia could therefore be a sign of phenotypic plasticity or early evolution of reproductive capacity (Kato 1995).
This hypothesis may only be addressed through longterm individual monitoring of females with calves using genetic and photographic capture-recapture.

Finally, a high reproductive capacity in Oceania could be due to food availability in the Southern Ocean. Indeed, in capital breeding populations (which accumulate resources before producing offspring at a later time, Sainmont et al. 2014), the quantity of food accumulated during the feeding season influences the breeding capacity during the next breeding season (e.g. Southern right whale Eubalaena australis, Leaper et al. 2006). Studies have highlighted that female humpback whales that have access to food in larger quantities and of better quality were more likely to produce healthy calves (Robbins 2007) and to have more post-partum ovulations (Chittleborough 1958, Dolphin 1985). As a third hypothesis, higher reproductive capacities in the Southern Hemisphere, and particularly in Oceania, could be supported by enhanced food resources compared to those of the Northern Hemisphere feeding grounds (Pallin et al. 2018). Studying historical and contemporaneous prey availability in Southern and Northern hemisphere feeding grounds would contribute to answering this question.

\section{CONCLUSIONS}

This study provides the first estimate of reproductive parameters for the New Caledonian part of the Endangered Oceania population of humpback whales and revealed calving intervals between 2.83 and $1.49 \mathrm{yr}$. These potentially short calving intervals corroborate differences highlighted by Wedekin et al. (2017) between the Northern and Southern hemisphere humpback whales, and could have contributed to the growth rate observed in New Caledonia following the ban on commercial whaling. Three non-exclusive hypotheses are proposed to explain potentially high reproductive capacities in Oceania humpback whales: age structure, phenotypic plasticity and prey availability. This study contributes to a global understanding of the dynamics of recovery for a cosmopolitan species following intense exploitation.

Acknowledgements. We thank the volunteers who participated in the fieldwork. Our acknowledgments go to D. Boillon, H. Bourgogne, J. Burgess, M. Chambellant, R. Dodemont, M. Oremus, V. Perard, M. Poupon and A. Schaffar. We thank Dr. J. Robbins and Dr. J. Jackson for their input in the early stages of the analysis. The manuscript was improved with constructive comments and editing from Dr. E. Garland and L. Pallin. Financial support was partly provided by the 
Fondation d'Entreprises Total; International Fund for Animal Welfare; Provinces Sud, Nord and Iles of New Caledonia; Total Pacifique; and Vale S.A. This study was carried out following the marine mammal treatment guidelines of the Society for Marine Mammalogy. Fieldwork was undertaken under permits issued by the Environment Department of the Provinces Sud and North of New Caledonia.

\section{LITERATURE CITED}

Aasen E, Medrano JF (1990) Amplification of the ZFY and ZFX genes for sex identification in humans, cattle, sheep and goats. Nat Biotechnol 8:1279-1281

Baker CS, Perry A, Herman LM (1987) Reproductive histories of female humpback whales Megaptera novaeangliae in the North Pacific. Mar Ecol Prog Ser 41:103-114

Baker CS, Steel D, Calambokidis J, Falcone E and others (2013) Strong maternal fidelity and natal philopatry shape genetic structure in North Pacific humpback whales. Mar Ecol Prog Ser 494:291-306

Barlow J, Clapham P (1997) A new birth-interval approach to estimating demographic parameters of humpback whales. Ecology 78:535-546

Barnosky AD, Matzke N, Tomiya S, Wogan GO, Swartz B, Quental TB, Mersey B (2011) Has the Earth's sixth mass extinction already arrived? Nature 471:51

Bonneville C, Anderson M, Baker CS, Schmitt N, Steel D, Oremus M, Garrigue C (2017) Temporal and spatial investigation of genetic diversity in humpback whales (Megaptera novaeangliae) wintering in New Caledonia. 2nd Humpback Whale World Congress, Reunion Island, 3-7 July 2017

Brodie PF (1975) Cetacean energetics, an overview of intraspecific size variation. Ecology 56:152-161

Brown M, Corkeron P, Hale PT, Schult KW, Bryden MM (1995) Evidence for a sex-segregated migration in the humpback whale (Megaptera novaeangliae). Proc R Soc B 259:229-234

Burnham KP, Anderson DR (2002) Model selection and multimodel inference: a practical information-theoretic approach. Springer, New York, NY

Caughley G (1966) Mortality patterns in mammals. Ecology 47:906-918

Childerhouse S, Jackson J, Baker CS, Gales N, Clapham PJ, Brownell RL Jr (2008) Megaptera novaeangliae (Oceania subpopulation). IUCN Red List Threat Species Version 20132:2007-2010

Chittleborough RG (1958) The breeding cycle of the female humpback whale, Megaptera nodosa (Bonnaterre). Mar Freshw Res 9:1-18

Chittleborough RG (1965) Dynamics of two populations of the humpback whale, Megaptera novaeangliae (Borowski). Mar Freshw Res 16:33-128

Choquet R (2008) Automatic generation of multistate capture-recapture models. Can J Stat 36:43-57

Choquet R, Rouan L, Pradel R (2009) Program E-SURGE: a software application for fitting multievent models. In: Thomson DL, Cooch EG, Conroy MJ (eds) Modeling demographic processes in marked populations. Springer, New York, NY, p 845-865

Civil MA, Cheney B, Quick NJ, Thompson PM, Hammond PS (2017) A new approach to estimate fecundity rate from inter-birth intervals. Ecosphere 8:e01796

Clapham P, Baker C (2002) Whaling, modern. In: Perrin WF,
Würsig B, Thewissen JGM (eds) Encyclopedia of marine mammals. Academic Press, San Diego, CA, p 1328-1332

Clapham P, Mayo CA (1987) Reproduction and recruitment of individually identified humpback whales, Megaptera novaeangliae, observed in Massachusetts Bay, 19791985. Can J Zool 65:2853-2863

Clutton-Brock TH (1984) Reproductive effort and terminal investment in iteroparous animals. Am Nat 123:212-229

Conover DO, Munch SB, Arnott SA (2009) Reversal of evolutionary downsizing caused by selective harvest of large fish. Proc R Soc B 276:2015-2020

Constantine R, Jackson JA, Steel D, Baker CS and others (2012) Abundance of humpback whales in Oceania using photo-identification and microsatellite genotyping. Mar Ecol Prog Ser 453:249-261

Craig AS, Herman LM (2000) Habitat preferences of female humpback whales Megaptera novaeangliae in the Hawaiian Islands are associated with reproductive status. Mar Ecol Prog Ser 193:209-216

Dawbin WH (1966) The seasonal migratory cycle of humpback whales. In: Norris KS (ed) Whales, dolphins and porpoises. University of California Press, Berkeley, CA, p $145-170$

Derville S, Torres LG, Lovan C, Garrigue C (2018) Finding the right fit: comparative cetacean distribution models using multiple data sources and statistical approaches. Divers Distrib 24:1657-1673

* Derville S, Torres LG, Dodémont R, Perard V, Garrigue C (2019) From land and sea, long-term data reveal persistent humpback whale (Megaptera novaeangliae) breeding habitat in New Caledonia. Aquat Conserv 29:1697-1711

Dolphin WF (1985) Food availability may measurably affect reproductive success in humpback whales. Abstr6th Bienn Conf Biol Mar Mamm, Vancouver, BC, 22-26 November 1985. Society for Marine Mammalogy, Lawrence, KS

Gabriele CM, Straley JM, Mizroch SA, Baker CS, Craig AS, Herman LM, Darling J (2001) Estimating the mortality rate of humpback whale calves in the central North Pacific Ocean. Can J Zool 79:589-600

Gaillard JM, Yoccoz NG (2003) Temporal variation in survival of mammals: a case of environmental canalization? Ecology 84:3294-3306

*Gamelon M, Gimenez O, Baubet E, Coulson T, Tuljapurkar S, Gaillard JM (2014) Influence of life-history tactics on transient dynamics: a comparative analysis across mammalian populations. Am Nat 184:673-683

Garrigue C, Greaves J, Chambellant M (2001) Characteristics of the New Caledonian humpback whale population. Mem Queensl Mus 47:539-546

Garrigue C, Aguayo A, Amante-Helweg V, Baker CS and others (2002) Movements of humpback whales in Oceania, South Pacific. J Cetacean Res Manag 4:255-260

Garrigue C, Dodemont R, Steel D, Baker CS (2004) Organismal and 'gametic' capture-recapture using microsatellite genotyping confirm low abundance and reproductive autonomy of humpback whales on the wintering grounds of New Caledonia. Mar Ecol Prog Ser 274:251-262

Garrigue C, Baker CS, Constantine R, Poole M and others (2011) Movement of individual humpback whales between the breeding grounds of Oceania (South Pacific) 1999 to 2004. J Cetacean Res Manag Spec Issue 3:275-281

Garrigue C, Albertson R, Jackson JA (2012) An anomalous increase in the New Caledonia humpback whales breeding sub-stock E2. Rep SC/64/SH6 to the Int Whaling Comm Sci Comm 
Garrigue C, Constantine R, Derville S, Dodemont R, Pérard V (2016) Kermadec Islands constitute a migratory corridor for New Caledonian humpback whales. In: Golder B, Connell A (eds) Proceedings of Kermadec-discoveries and connections. The Pew Charitable Trusts, Wellington, p 51-53

Garrigue C, Bonneville C, Derville S, Dodemont R, Oremus M, Pérard V (2017) Humpback whale offshore breeding grounds in the South Pacific: unravelling the network. 22nd Bienn Conf Biol Mar Mamm, Halifax, NS, 22-27 October 2017

Garrigue C, Bonneville C, Derville S, Dodemont R and others (2018) Rapport des campagnes MARACAS 3,4 \& 5

Genovart M, Pradel R (2019) Transience effect in capturerecapture studies: the importance of its biological meaning. PLOS ONE 14:e0222241

Gilson A, Syvanen M, Levine K, Banks J (1998) Deer gender determination by polymerase chain reaction: validation study and application to tissues, bloodstains, and hair forensic samples from California. Calif Fish Game 54: 159-169

Gimenez O, Lebreton JD, Choquet R, Pradel R (2018) R2ucare: an R package to perform goodness-of-fit tests for capture-recapture models. Methods Ecol Evol 9: 1749-1754 https://github.com/oliviergimenez/R2ucare

IWC (International Whaling Commission) (2005) Report of the sub-committee on other Southern Hemisphere whale stocks. J Cetacean Res Manag 7(Suppl):235-244

Jackson JA, Ross-Gillespie A, Butterworth DS, Findlay K and others (2015) Southern Hemisphere humpback whale comprehensive assessment-a synthesis and summary: 2005-2015. Rep SC/66a/SH3 to the Int Whaling Comm Sci Comm

Kato H (1995) Migration strategy of southern minke whales to maintain high reproductive rate. Dev Mar Biol 4:465-480

Katona SK, Whitehead HP (1981) Identifying humpback whales using their natural markings. Polar Rec (Gr Brit) 20:439-444

Lambertsen RH (1987) A biopsy system for large whales and its use for cytogenetics. J Mammal 68:443-445

Leaper R, Cooke J, Trathan P, Reid K, Rowntree V, Payne R (2006) Global climate drives southern right whale (Eubalaena australis) population dynamics. Biol Lett 2:289-292

Lebreton JD (2006) Dynamical and statistical models of vertebrate population dynamics. C R Biol 329:804-812

Minton G, Collins T, Pomilla C, Findlay KP, Rosenbaum H, Baldwin R, Brownell RL Jr (2008) Megaptera novaeangliae (Arabian Sea subpopulation). IUCN Red List Threat Species 2008

Murphy EJ, Watkins JL, Trathan PN, Reid K, Meredith MP, Thorpe SE (2007) Spatial and temporal operation of the Scotia Sea ecosystem: a review of large-scale links in a krill centred food web. Philos Trans R Soc B 362:113-148

Olavarría C, Baker CS, Garrigue C, Poole M and others (2007) Population structure of South Pacific humpback whales and the origin of the eastern Polynesian breeding grounds. Mar Ecol Prog Ser 330:257-268

Orgeret F, Garrigue C, Gimenez O, Pradel R (2014) Robust assessment of population trends in marine mammals applied to New Caledonian humpback whales. Mar Ecol Prog Ser 515:265-273

Pallin LJ, Baker CS, Steel D, Kellar NM and others (2018)

Editorial responsibility: Peter Corkeron,

Woods Hole, Massachusetts, USA
High pregnancy rates in humpback whales (Megaptera novaeangliae) around the western Antarctic Peninsula, evidence of a rapidly growing population. $\mathrm{R}$ Soc Open Sci 5:180017

*Pimm SL, Jenkins CN, Abell R, Brooks TM, Gittleman JL, Joppa LN, Sexton JO (2014) The biodiversity of species and their rates of extinction, distribution, and protection. Science 344:1246752

* Polanowski AM, Robbins J, Chandler D, Jarman SN (2014) Epigenetic estimation of age in humpback whales. Mol Ecol Resour 14:976-987

* Pradel R (2005) Multievent: an extension of multistate capture-recapture models to uncertain states. Biometrics 61 : 442-447

* Pradel R, Wintrebert CMA, Gimenez O (2003) A proposal for a goodness-of-fit test to the Arnason-Schwarz multisite capture-recapture model. Biometrics 59:43-53

Pradel R, Gimenez O, Lebreton JD (2005) Principles and interest of GOF tests for multistate capture-recapture models. Anim Biodivers Conserv 28:189-204

Ramp C, Bérubé M, Palsbøll P, Hagen W, Sears R (2010) Sex-specific survival in the humpback whale Megaptera novaeangliae in the Gulf of St. Lawrence, Canada. Mar Ecol Prog Ser 400:267-276

Rankin RW, Maldini D, Kaufman G (2014) Bayesian estimate of Australian humpback whale calving interval under sparse resighting rates: 1987-2009. J Cetacean Res Manag 13:109-121

Riekkola L, Zerbini AN, Andrews O, Andrews-Goff V and others (2018) Application of a multi-disciplinary approach to reveal population structure and Southern Ocean feeding grounds of humpback whales. Ecol Indic 89:455-465

Robbins J (2007) Structure and dynamics of the gulf of marine humpback whale population. PhD thesis, University of St. Andrews

Rosenbaum HC, Weinrich MT, Stoleson SA, Gibbs JP, Baker CS, DeSalle R (2002) The effect of differential reproductive success on population genetic structure: correlations of life history with matrilines in humpback whales of the Gulf of Maine. J Hered 93:389-399

* Sainmont J, Andersen KH, Varpe Ø, Visser AW (2014) Capital versus income breeding in a seasonal environment. Am Nat 184:466-476

Steel D, Anderson M, Garrigue C, Olavarría C and others (2018) Migratory interchange of humpback whales (Megaptera novaeangliae) among breeding grounds of Oceania and connections to Antarctic feeding areas based on genotype matching. Polar Biol 41:653-662

Tønnessen JN, Johnsen AO (1982) The history of modern whaling. University of California Press, Berkeley, CA

Valsecchi E, Corkeron PJ, Galli P, Sherwin W, Bertorelle G (2010) Genetic evidence for sex-specific migratory behaviour in western South Pacific humpback whales. Mar Ecol Prog Ser 398:275-286

Wedekin LL, Engel MH, Andriolo A, Prado PI and others (2017) Running fast in the slow lane: rapid population growth of humpback whales after exploitation. Mar Ecol Prog Ser 575:195-206

Zerbini AN, Clapham P, Wade PR (2010) Assessing plausible rates of population growth in humpback whales from life-history data. Mar Biol 157:1225-1236

Submitted: October 24, 2018; Accepted: April 14, 2020

Proofs received from author(s): May 18, 2020 